Hoffman's achievement will be best appreciated by those most familiar with the extent and ramification of technical assistance and technical co-operation in any sphere. It is addressed primarily to the American reader and the figures for aid which are quoted relate largely to the contribution of the United States. While the exposition is too clear and vivid for this to hinder any British reader from grasping the extent of the problem or the urgency of the chal. lenge, the excellence of the book would justify the inclusion in any subsequent reprint in Britain of a note on Britain's effort, even if only condensed from the White Paper on Overseas Aid or the pamphlets of the Overseas Development Institute. Poignancy is added to the present interest of the book by the commendations on the cover from two former Presidents of the United States; few books have dealt so vividly with a subject which lay so closely to the heart of the late President Kennody-the task of eliminating poverty and hunger from the world and helping the backward pooples to do this for themselves.

\section{The Incubation Period of Coronary Thrombosis}

By G. R. Osborn. Pp. $x+190$ (figures). (London: Butterworth and Co. (Publishers), Ltd., 1963.) 55s.

T HE results of a painstaking histological study are presented in this book with profuse illustration so that it provides an atlas of the pathology of coronary artery disease. Although fully developed lesions are studied in detail, there is much emphasis on the early stages of the disease, and it is here that an improved understanding of the pathological changes may have the greatest therapeutic implications.

It is clear that coronary artery disease is not an inevitable result of ageing, but the picture emerging from this study is of a disease beginning in childhood and adolescence. Early mucoid changes are noted in the arterial wall, and it is suggested that the later accumulation of lipid may be a secondary complication rather than the primary cause of the lesions. The later development of fibrosis and necrosis, vascularization and calcification is followed in detail, and the part played by thrombosis in the later stages is analysed. The effects on the vascular lumen are shown in the form of serial sections.

The usefulness of the analysis to the general reader is somewhat diminished by the lack of a clear statement of the conclusions derived from the histological study. Nevertheless, it is a valuable contribution to this facet of coronary artery disease. JOHN HAMER

\section{Conditioning Factors for Cardiac Necroses}

By Eörs Bajusz. Pp. viii + 327. (Basle and New York: S. Karger, 1963.) S.Fr./D.M.75.

$\mathrm{T}$ HIS is an unusual monograph describing a series of researches conducted over several years in the Institute of Experimental Medicine of the University of Montreal. The author has demonstrated that the production of myocardial necrosis in animals by entirely different noxious stimuli may be uniformly aggravated or suppressed by certain agents which are considered to be conditioning factors. Numerous specific experiments are described in this treatise to illustrate the general principle that disease is a biological expression of inadequate adaptation resulting from conditioning influences. As pointed out by Hans Selye in the foreword, there is nothing new in the view that many diseases are due to multiple factors; however, this monograph illustrates some of the mechanisms through which pluricausal diseases can develop. Although the application of this experimental work to clinical problems is sometimes clearly indicated much of it seems rather remote from clinical medicine: this is inevitable because of the lack of data concerning the cause of focal necrotizing cardiomyopathies in man. Clinical cardiologists and laboratory workers will find much of interest in the pages of this monograph. W. BRIDGEN
Cardiac Output and Regional Blood Flow

By Prof. O. L. Wade and Dr. J. M. Bishop. Pp. xv +268 . (Oxford: Blackwell Scientific Publications, 1962.) 458.

CARDIAC Output and Regional Blood Flow provides $C$ an excellent review of the present knowledge concerning cardiac output and regional blood flow together with a synthesis of the original work carried out on this subject in the department of medicine of the Birmingham Medical School. An interesting introduction by Prof. K. Donald describes the evolution of this research, and the first six chapters are concerned with the measurement of cardiac output in man and normal physiology. Subsequent chapters deal with hæmodynamic problems in heart disease.

This is probably the most authoritative account of the subject so far prepared. It is clearly writton, well illustrated and there is a good bibliography. This monograph may be firmly recommended to clinicians, physiologists and others interested in the subject.

W. BRIGDEN

\section{Psychology and Religion}

An Introduction to Contemporary Views. By G. Stephens Spinks. (Methuen's Manuals of Modern Psychology.) Pp. $x v+221$. (London: Methuen and Co., Ltd., 1963.) $28 s$.

$\mathrm{M}$

ANY writers, from William James onwards, have attempted to analyse and explain religious experience and behaviour in psychological terms. Psychology and Religion presents a well-ordered and readable review of this literature which is often tedious and difficult to understand in its original form. There are two main sections. The first deals with theories regarding the nature of religion and surveys a number of views put forward by philosophers, anthropologists and psychologists as a prelude to a fuller treatment of the ideas of Freud and Jung. The second part is concerned with attempts to analyse different types of religious experience and practice, such as prayer and worship; it again draws heavily on anthropological data and also on comparative religion as well as on specifically Christian sources. The book is scholarly throughout and is enlivened by many penetrating observations and stimulating comments. It is, in my opinion, by far the best survey in this field since R. H. Thouless's book, Introduction to the Psychology of Religion, published in 1924 .

Yet it must be admitted that in one respect it is disappointing; it is not really a manual of modern psychology. With only sporadic exceptions, it stops short at Froud and Jung. Predominantly it reflects the arm-chair pontification of half a century ago. There is no sustained effort to translate ideas into the idiom of present-day clinical, social or experimental psychology and to see what implications these might have for religious practice and thought. In this respect the book contrasts markedly with Gordon Allport's The Individual and his Religion published in 1951, which makes a truly modern analysis of certain aspects of religious attitude, and with Michael Argyle's Religious Behaviour, published in 1958, which casts propositions about the function of religion in human affairs in a manner which enables them to bo tested by controlled, scientific research. Neither of these books has the wido coverage of the present work, but they are genuinely representative of contemporary psychology and show something of what it could be doing in the examination of roligion to-day.

What this book does do is to provido an exeellent, outline of traditional approaches to the psychology of religion. The genoral reader who takes religion seriously will find much in it that provokos thought and helps towards a balanced perspective, while anyono wishing to study religion from a psychological point of view has a concise and authoritative historical introduction.

A. T. WELFORD 